\title{
Air Conditioning System Energy Saving Diagnosis Method based on Operating Data Research
}

\author{
Yue Xingzuo \\ Wuhan Institute of Shipbuilding Technology \\ 84771162@qq.com \\ Wuhan China
}

\begin{abstract}
In recent years, in view of existing air conditioning system energy saving diagnosis research has been closely watched. As a typical air conditioning system energy saving diagnosis method, the observation/ac test/computing - judgment/solution I"(the OTI) method is widely used in the practical project diagnostic analysis, but at the same time, this method also has some shortcomings. This approach requires system based on the actual situation, for example, artificial selection diagnostic index, and then for testing and evaluation. And in the actual process of diagnosis, also need to change, adjust to adapt to the needs of each project. That said, this approach has been limited to a concrete analysis of concrete problems. In recent years, many researchers have been trying to let hair and improve the diagnosis of energy saving, new and old methods, but in terms of existing methods, its essence content is still not beyond the category of the OTI diagnosis methods, so to speak nothing diagnosis method of revolutionary change. System operation data, on the other hand, is the actual air conditioning system running status, the most direct, most real reflection, which run through the automatic monitoring data and take the corresponding optimization to reduce the system energy consumption become an important way to realize the air-conditioning energy saving. At present, many building air conditioning system has been running data acquisition, a large amount of data accumulated in the process of operation for the data analysis system on energy consumption and operation provides the basis. However, a large amount of data also brought I"data disasterl", makes it hard for managers quickly and efficiently find abnormal energy waste and energy consumption problems.
\end{abstract}

Keywords-conditioning system; the run data; energysaving diagnosis; energy saving potential analysis; particle swarm optimization algorithm.

\section{INTRODUCTION}

The development of human now faces a serious energy and environmental problems. Global construction contribution to the rapid growth of energy consumption, including residential and commercial buildings, in developed countries has been growing steadily to $20 \%$ $40 \%$ of the country's energy consumption. In China, this proportion is as high as $9.1 \%$. And in building can equipment, air conditioning system accounts for $50 \%$ of the total energy consumption of the whole building, become the largest energy consumption in residential and non-residential building terminals. That is to say, the energy consumption of air conditioning system has accounted for one over ten of global energy consumption. Energy-saving research to reduce building energy consumption of air conditioning system, and for the promotion of economic and social sustainable development, has the very vital significance.

According to the requirements of the air conditioning system related design standards, air conditioning system must be designed according to meet the most unfavorable situation when load, namely, said an actual air conditioning system must meet the requirements of air conditioning area maximum load. However, the actual cases systems rarely work under these conditions limit (or full), most of the time is running under partial load. Therefore, it is in fact did a lot of surplus space to the system. According to the statistics, central air conditioning system is under $70 \%$ load running time is about $97 \%$ of the system running time.

\section{THE PROBLEMS OF EXISTING CIVIL BUILDING AIR CONDITIONING SYSTEM IN THE DESIGN, OPERATION, MAINTENANCE AND MANAGEMENT}

For the existing civil building air conditioning system in the design, operation, maintenance and management and the following serious problem:

1. In the first place in the process of system design is "equipment selection is high and not low, peaceful big not small, rely too much on designers experience" of the design thought and practice, "large flow of small temperature difference", "fluid pipeline network hydraulic imbalance", eventually led to the system in the actual operation efficiency is low.

2 . When the air conditioning system of the completion of commissioning, the lack of a complete set of effective engineering performance testing, supervision, acceptance mechanism.

3. In the process of system operation, hot wet air conditioning area environment parameters meet the design requirements, power equipment whether reach the design output, energy supply system is efficient and the running efficiency of the key problems, such as size, for users or run the maintainer, are the basic unknown, and these unknown running state just contain the huge energy saving potential.

4. In the process of system operation maintenance, because there is no direct effective reference for the operation of the tool and the correct data, operation maintenance personnel to determine whether a system is in 
normal state mostly rely on experience or only depends on whether the corresponding equipment operation to judge, this way there is a big hidden trouble, reduce the system operation reliability, of course also contains energy saving potential.

5. In terms of system operation and management, operation management view of operation and energy saving still stays in the "using less consumption less, don't open the most energy saving" misconceptions, at the expense of the indoor personnel comfort this rough way to realize the energy saving operation, which often cause indoor environment temperature and humidity fluctuations. Another under partial load conditions, using intermittent operation mode, frequent start-stop devices, both affect the equipment service life, and not achieve the goal of real energy saving.

\section{AIR CONDITIONING SYSTEM IN THE ACTUAL} OPERATION OF THE STATUS OF THE "HIGH CONSUMPTION INEFFICIENT", INVESTIGATE ITS REASON

For air conditioning system in the actual operation of "high consumption inefficient" situation, the reasons can be summarized as:

1. The air conditioning system design method is not scientific.

While in the air conditioning system design in the standard provision: \"except in the design or preliminary design stage can use heat, cooling load indicators to estimate, construction drawing design phase to deal with air conditioning the hourly cooling load in summer and winter heating load calculation \", at the same time, with the increasingly improvement of simulation analysis software, but in the actual air conditioning system design, the design unit most still exists in the traditional estimation method, including air conditioning system, especially in refrigeration host, fruit and other large equipment type selection, buried the hidden trouble of the energy waste.

2 . The lack of energy consumption quota standards.

In our country, the state council in August 2012 and January 2013, successively introduced the 12th five-year plan for energy conservation and emissions reduction and the "energy" twelfth five-year "development planning" respectively, puts forward the country's public institutions unit building area of energy intensity indicators, as well as the total energy consumption and power consumption indicators, but this and pass some quantitative energy consumption quota to guide the energy saving of airconditioning system still has a long way to run the expectations. At present, the national related department are working on the building energy consumption standards, are going to start from the total amount control is given building can limit reference, tried to building energy conservation work step by step from ।"how tol" to \"how much energy consumption \". But due to differences in climate type in our country, building types, changeful meteorological parameters, types of air conditioning system and the actual use differ in thousands ways, using upper limit to control energy consumption, operation energy consumption evaluation system, its applicability and effectiveness of energy saving potential of specific system is a have to worry about.

3. The system is running low maintenance.
In addition to the front in this paper has described the operation of the maintenance problems, in the process of system operation, although some construction claims to be "intelligent building", "green building", but because of the automatic control and air conditioning design, construction and commissioning, quite a part of the system to run the effect not beautiful. And is an automatic control system of air conditioning system in practice, there are also no use. In addition, there are many at the beginning of building air conditioning equipment does not pass, systems and equipment of self-control can't play a role, not only equipment adjustment is not appropriate, maintenance is not timely, loss accelerated facilities; Also makes the pipe beside the pond, eventually lead to the operation of the system operation process related control parameters have serious lag, cause disorder of system control and energy waste.

\section{AIR CONDITIONING SYSTEM RUNNING DATA CASE AND UNDERSTAND}

In order to better surface-to-air tuning system energy saving diagnosis method, the research work in this paper chooses a typical case, and the method of combining the research results, to show the whole process of case analysis and research.

Define abbreviations and acronyms the first time they are used in the text, even after they have been defined in the abstract. Do not use abbreviations in the title or heads unless they are unavoidable.

A. The system is a typical and wide coverage. Obviously, the ice storage air conditioning system is under subsection requires an ideal choice,

due to its "compound" constitute the characteristics of the system itself, from the system (for) the complexity of the cooling system, basically just on the basis of its do "subtraction" can form other types of air conditioning system.

B. The system monitoring points.

In order to get the actual data to compare the comprehensive reflection of the system running situation and requirement as far as possible more point test data, and makes some relevant relations, can each other in order to verify the data analysis system running situation more accurately.

C. The quantitative data set higher frequency.

Process of air conditioning system is a process of strong time-varying effect, a parameter within a running average data or summary data obviously cannot really reflect the system within a day of running state, the higher frequency is the analysis, the examination system by the quantitative data set the important guarantee of running state.

$D$. A representative data. Without the operation of the all-year hourly data, you need to request system run data with the general representative of air conditioning season. In fact, it is difficult to measure. In actual operation, often can transform a train of thought, is the required data startstop span is larger, the reason for this can be a home air conditioning season longer or characteristics lead to air conditioning running time is long, etc. 


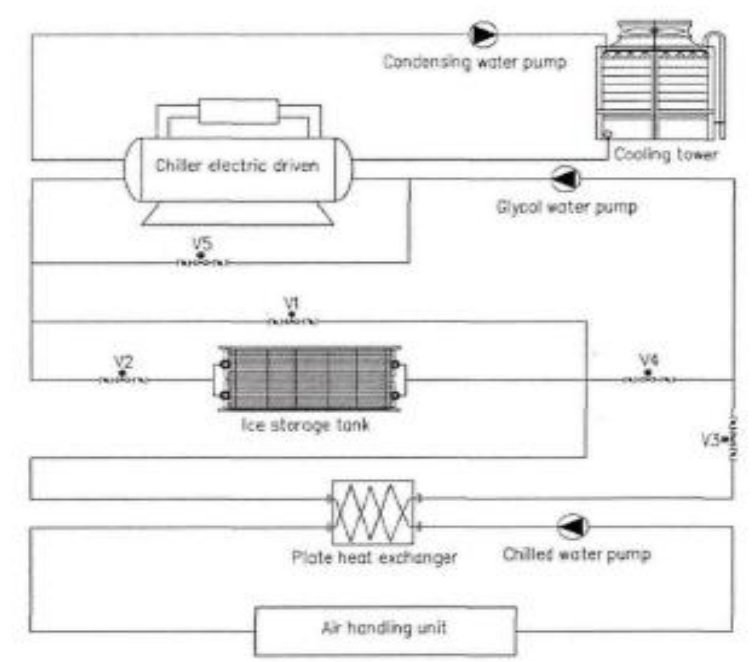

Figure 1. the ice storage air conditioning system schematic

\section{ENERGY CONSUMPTION OF AIR CONDITIONING SYSTEM DIAGNOSIS METHOD OF TIME AND SPACE AND DATA PREPROCESSING}

First of all, on the air conditioning system operation data preprocessing, diagnostic work in order to achieve the data quality and professional requirements.

Secondly, the use of modern information and data analysis tools will be pre-processed data from the energy consumption of time and space distribution of the two aspects, respectively on the equipment running time, operation time, stop order and system energy consumption and efficiency were analyzed, and concluded that system energy by using effective and orderly degree of various energy-using equipment and system operation energy consumption, the preliminary evaluation of strategy and operation benefits. It should be pointed out that, this part of the analysis process won't conducted on time distribution and space distribution strict distinction and restrictions, in theory, the whole process should have both cross even interaction.

The using artificial intelligence optimization algorithm, the maximum energy saving potential of system optimization, the final diagnosis and energy-saving air conditioning system energy saving potential conclusions.

When the same variable has two or more than two times of the data, it means there is a time series, analysis of such data is often can use the time series analysis. However, the word "time series analysis" usually refers to analysis with long time series of single case in a series of methods. Different Time Series Analysis of types including autoregressive Moving Average model of Time Series Regression (Time Series Regression, TSR) model, Lag of Endogenous variable (Lag of them the Endogenous Variables, LEV) model, Spectral Analysis, Spectral Analysis), etc. In order to distinguish, this chapter mainly adopt the method of longitudinal study began to show. Longitudinal study has two main purposes, one is to describe the patterns of change, the second is to establish the direction of the association or causality, both of which will be covered in this chapter. In this article, the word and not a single or a set of methods, but can realize the data throughout the study. A Series of similar methods of

Energy-using equipment is frequency conversion equipment and the working characteristic of the frequency conversion situation, will affect after correlation analysis, while the answers to such questions can be gained through the field investigation and research, but in order to makes the study of this paper is more universal, this section will make use of the energy consumption data analysis, the research on this issue.

Based on the investigation of energy consumption data of digital features and feature selection, and found the coefficient, variation coefficient and kurtosis coefficient can be used to determine the system frequency characteristics of water dish, at the same time, through the digital characteristics and the analysis and research of the determination coefficient itself requires, defines a calculation more simple $4 \mathrm{~m}$ coefficient, to determine the frequency conversion equipment features, through actual case show that the identification effect is better than before three coefficients.

Through the analysis of the equipment operation time and operation time, found that case the operation of air conditioning system control method and control strategy problems still exist. Only by the offside operation of this kind of situation leads to a waste of energy costs will account for $3.8 \%$ of the total energy costs, this is also the most basic the system energy saving potential.

With pattern recognition system conditions, this chapter firstly choose the DBSCAN clustering algorithm based on density data of energy consumption of the system were analyzed, by adjusting the algorithm parameter is set, finally got more accord with the theory and the actual results, at the same time, the result also shows that M3 condition may be offside operation of the equipment. On this basis, continue to use the CART algorithm and interactive modeling method to establish the system working mode of the decision tree classification model, through the classification results of each check, found its classification result is good, at the same time, the result 
also shows that offside operation condition appeared a lot of equipment.

For similar case section of ice storage air conditioning system for potential calculation algorithm needs summarized as follows:

1. For each accumulation of cold, cold release cycles, each period according to the cooling load demand, according to the constraint conditions on the air conditioning system operation optimization calculation.

2. For a cold storage, cold release cycle each time, each period according to the cooling load demand and characteristics of time and to determine the working condition.

3. The meter for each identified as joint time and cooling condition, needs to randomly determine the ice storage device and host each cooling rate.

4. In view of the produced by the above each step of each set of parameters, all according to the algorithm, this paper first 7.3.5 section calculation of cooling machine total energy costs.

5. Through continuous adjustment of cycle conditions and other parameters, the minimum cost of energy consumption optimization.

\section{CONCLUSIONS}

In view of the air conditioning system energy saving diagnosis problem, this paper puts forward an energysaving diagnosis method based on the air conditioning system operation data, running through the system data in time and space distribution is analyzed, digging, study the system operation characteristics, and by using optimization algorithms to optimization calculation of running the benchmark energy costs, relevant results for air conditioning system energy saving potential quick judgment and system energy saving optimization provides important decision basis. The main research conclusions summarized as follows:

1. Typical air conditioning system energy saving diagnosis methods at the present time and based on the deficiency of the understanding of operational data, this paper puts forward a new method for diagnosis of energy saving - energy diagnosis method of time and space. This method not only less consumption of time and manpower resources, generality, better scalability, and its diagnosis is both method is more practical, more reliable, at the same time it also can complete all the individual problems of the system energy consumption activity elements and has practical significance of research of combined type, expanding the research scope of the diagnosis of energy consumption.

2. In the analysis of the energy consumption of air conditioning system time distribution process, this paper based on the investigation of energy consumption data of digital features and feature selection, variation coefficient and kurtosis coefficient can be used to judge the system frequency characteristics of water millet, at the same time, through the digital characteristics and the analysis and research of the determination coefficient itself requires, defines a calculation more simple $4 \mathrm{~m}$ coefficient, to determine the frequency conversion equipment features, through actual case show that the identification effect is better than before three coefficients.

3. In the process of the analysis of the spatial distribution of energy consumption of air conditioning system, in view of the system working condition of pattern recognition, this paper chooses the DBSCAN clustering algorithm based on density data of energy consumption of the system were analyzed, by adjusting the algorithm parameter is set, finally got more accord with theoretical and practical results. On this basis, this paper studies use classification and regression tree CART algorithm and the calculation of interactive way of modeling system working mode of the decision tree classification model is established, based on the classification results of each inspection, found that the classification effect is good. In refrigeration host characteristics represented by the multivariate regression equipment operation energy consumption characteristics in the process of research, this article embarks from the professional point of view, combined with the practical operation of refrigeration host, proposed based on the interaction between the independent variables, the higher order term and the fitting effect and so on multiple levels to establish and select the principle of fitting model.

\section{REFERENCES}

[1] Arroyo V Agenda for climate action [R]. Arlington, VA,USA: Pew Center on Global Climate Change, 2006.

[2] MaRJ, YiiNY, HuJYApplication of particle swarm optimization algorithm in the heating system planning problem [J], Scientific World Journal, 2013,Article 718345.

[3] Mcquistion F C,Parker J D,Spitler J D. Heating, Ventilating, and Air Conditioning analysis and design [M], John Wiley \& Sons, Inc., 2005.

[4] SHRAE. ANSI/ASHRAE/CESNA Standard 90.1, Eneigy standard for buildings except ow-rise residential buildings [S]. Atlanta, USA: ASHRAE, Inc., 2010.

[5] Lee W L, Vik F W H. Regulatory and voluntaiy approaches for enhancing energy efficiencies of buildings in Hong Kong [J]. Applied Energy, 2002,71(4): 251-274.

[6] Perez-Lombard L, Ortiz J, Coronel J F,et al. A review of HVAC systems requirements in building enei regulations $[\mathrm{J}]$. Eneigy and Buildings, 2011,43(2-3): 255-268

[7] Canbay C S,Hepbasli A,Gokcen G. Evaluating performance indices of a shopping centre and implementing HVAC control principles to minimize energy usage $[\mathrm{J}]$, Energy and Buildings, 2004, 36(6): 587-598.

[8] Visier J. Commissioning of building HVAC Systems for improving eneigy performance [R]. 1EA Aimex 40,2005

[9] Friedman H, Claridge D, Choini Re D,et al. Commissioning cost-benefit and persistence of savings[R]. IEA Annex 47,2011.

[10] Reddy T A, Niebur D, Andersen K K, et al. Evaluation of the suitability of different chiller performance models for on-line training applied to automated fault detection and diagnosis $[\mathrm{J}]$, HVAC\&R Research, 2003,9(4): 385-414. 